\title{
ROLE OF MANAGEMENT CONTROL SYSTEMS IN CRAFTING REALIZED STRATEGIES
}

\author{
David NARANJO-GIL \\ Pablo de Olavide University, Carretera Utrera Km.1, 41013 Sevilla, Spain \\ E-mail:dnargil@upo.es
}

Received 03 July 2013; accepted 01 December 2014

\begin{abstract}
The distinction between deliberate and emergent strategy implementation is rarely acknowledged in management control literature, which has promoted a passive view of control systems tailored explicitly to support the strategic planning. This paper analyzes how management control systems facilitate organizations to realize their intended strategies. Hypotheses are tested using survey data from CEOs of Spanish hospitals. Partial least squares is used as a statistical technique to test the integral causal path model. Results show that boundary and diagnostic control systems have primarily a positive impact on the realization of deliberate strategies, whereas belief and interactive control systems positively affect emergent strategies. This study tries to clarify the fragmented results of the literature by analyzing the effect of the design (passive role) and the use (active role) of management control systems on both deliberate and emergent strategies. A practical implication of this paper is that managers should focus on both the design and the use of management control systems to implement strategies successfully. This study is among the first to provide empirical evidence on how different levers of control complement each other in crafting realized strategies.
\end{abstract}

Keywords: management control system, levers of control, strategy management, deliberate strategy, emergent strategy, survey, hospitals.

JEL Classification: L20, M41, C83.

\section{Introduction}

In a more dynamic environment, organizations do not often accomplish their strategies as planned, since they are changed for a series of actions that emerge during the implementation process. Despite accumulated expertise, time, and resources devoted to strategic planning, the resulting strategies are rarely implemented successfully (Thompson et al. 2010; Mintzberg 1994). Generally the focus of past research has been on formulating strategies, while implementing strategies was theorized about but not tested (Snow, Hambrick 1980). Mintzberg $(1991,1994)$ stressed the ambiguous and messy nature of strategic decisions, and he recognized the need to distinguish between strategies intended and those actually realized or implemented (Mintzberg 1994; Mintzberg et al. 1998). Realized strategies may develop from those strategies formally planned, but it may also evolve from a new series of actions that converge to a consistent pattern called 
an emergent strategy (Langfield-Smith 2008; Nixon, Burns 2012). Deliberate strategies are patterns intended by the organization that are actually realized. Emergent strategies are the realized strategies that were never intended arising as patterns of actions that replace or change the deliberate strategies (Mirabeua, Maguire 2014; Thompson et al. 2010; Lowe, Jones 2004).

Since not all realized strategies arise in the same way, recently several management accounting researchers have claimed that more work needs to be done, not only towards understanding the role that control systems play in shaping the search for new initiatives, but also in understanding how control systems facilitate organizations to realize their intended strategies (Nixon, Burns 2010; Tessier, Otley 2012; Ismail 2013). However, the importance of the distinction between intended and realized strategy is rarely acknowledged in management accounting literature, which has promoted a passive view of management control as a system tailored explicitly to support the strategic planning (Ismail 2013; Cadez, Guilding 2012; Chenhall 2008). Management control systems are defined as the practices that managers use for maintaining or altering patterns within organizational activities, and also for implementing organization's strategies (Anthony, Govindarajan 2007). However, relatively little is known about how different management control systems are effective antecedents of the strategy implementation (Skaerbaek, Tryggestad 2010; Frigotto et al. 2013). Literature on strategic management accounting has traditionally examined intended strategy as an antecedent of management control systems, which are conceptualized as static systems that provide information for supporting strategy formulation rather than strategy implementation (Tessier, Otley 2012; Cadez, Guilding 2012). However, management control systems may not contribute to strategic goal achievement if intended strategies are never realized, due to change in plans during implementation (Ismail 2013; Skaerbaek, Tryggestad 2010; Frigotto et al. 2013). Based on levers of control framework (Widener 2007; Simons, 2000), this paper adopts a more comprehensive view of management control systems, and it analyzes simultaneously the role of four control systems (belief, boundary, diagnostic and interactive) in shaping the search for new strategic initiatives. This paper also analyzes how these four control systems facilitate organizations to realize their intended strategies. Thus, this study aims to achieve a better knowledge on how managers are able to handle the tensions and balances between the levers of control in order to implement strategies successfully.

Although research on the interaction between management control systems and strategy has been focused on private sector organizations, recently this topic has also begun to permeate in the public sector under the new public management paradigm (Modell 2012; Carter et al. 2010). We test our hypotheses using survey data from CEOs in the Spanish public hospital sector. As CEOs are ultimately responsible for strategy implementation, they can and will influence the realization of organizational strategy (Skaerbaek, Tryggestad 2010; Schultz et al. 2004). Results were analyzed using Partial Least Square, and they support generally our hypotheses.

This paper has several contributions. Firstly, it analyzes simultaneously the design (passive role) and the use (active role) of management control systems on strategy implementation. Secondly, this paper examines empirically the role of management control 
systems on facilitating organizations to implement both deliberate and emergent strategies (Mirabeua, Maguire 2014; Nixon, Burns 2012). That distinction on strategy is conceptually important and may partially explain the conflicting and fragmented results observed in the strategic management control literature (Langfield-Smith 2008; Ismail 2013). Thirdly, this paper looks at tensions and balances between different types of management control systems, and thus it provides empirical evidence on how different levers of control complement each other in crafting realized strategies (Tessier, Otley 2012; Simons 2000).

The remainder of this paper is organized as follows. Next section reviews the literature and develops hypotheses about the relationship between management control system and strategy. Then we describe the research method, and we present the results of the empirical analysis. Finally, the discussion and conclusions of this study are shown.

\section{Literature review and hypotheses development}

The term strategy has been defined in several ways with a common theme, that of a deliberate conscious set of guidelines that determines decisions into the future (Mintzberg 1978; Porter 1985). Under the called planning school flag, in many organizations strategic choices are made through a strategic planning process (Langfield-Smith 2008; Mintzberg et al. 1998). While not denying that formal analysis and planning has a role, some researchers on strategy have emphasized another view of strategy processes under the called learning school flag (Mintzberg 1994; Mirabeua, Maguire 2014). Mintzberg and Waters (1985) were one of the first authors to point out that realized strategies can strongly differ from intended strategies. They conceived strategy as a pattern in a stream of decisions or actions, and they distinguished between patterns deliberately created and patterns emerging in the absence of - or despite - intention. Mintzberg (1994) compared intended strategies with realized strategies, which allowed distinguishing deliberate strategies, which are realized as intended, from emergent strategies, which are patterns realized despite intentions (Mirabeua, Maguire 2014; Thompson et al. 2010). For a strategy to be perfectly deliberate there must have existed precise intentions in the organization, articulated in a relatively concrete level of details. For a strategy to be perfectly emergent, there must be order in the absence of intension about it (Mintzberg 1987, 1994; Mirabeua, Maguire 2014; Davies, Walters 2004). Conceptually a purely deliberate or emergent does not exist, as Mintzberg and Waters (1985) asserted it is difficult to imagine action in the total absence of intention. The assessment of the deliberate or emergent nature of a strategy process should include factors that capture the complex nature of the phenomenon, such as the number of strategic ends and means that are realized or the level of specificity of ends and means (Lowe, Jones 2004; Harrington et al. 2004). Strategic ends relate to what an organization desires to achieve, while strategic means relate to how an organization intends achieving these ends. That is, strategic means are action-oriented (Brews, Hunt 1999; Langfield-Smith 2008) ${ }^{1}$. Brews and Hunt (1999) argued that low specificity of ends and means is consistent with a more emergent strategy.

\footnotetext{
${ }^{1}$ Synonyms for strategic ends include mission, purposes, goals or objectives, synonyms for strategic means range from strategies or policies, to alternatives, programs or action plans.
} 
Contingency-based research has largely suggested that strategies require comprehensive management control systems to be realized successfully (Langfield-Smith 2008; Cadez, Guilding 2012). Management control systems are the practices through managers influence others members of the organization for implementing the strategy (Anthony, Govindarajan 2007; Simons 2000). Whilst deliberate strategy focuses on direction and control, emergent strategy suggests a learning process in the search for effective patterns of behavior and decision making outcomes (Frigotto et al. 2013; Langfield-Smith 2008). Thus, managers need management control systems, which assist them in developing viable patterns of behavior (Chenhall 2008) and in managing both deliberate and emergent strategies (Mirabeua, Maguire 2014; Simons 2000). Simons (1995, 2000) proposed a dynamic view of management control systems by combining a focus on strategy with a wider view of the control mechanisms that can be used to implement strategies (Tuomela 2005; Tessier, Otley 2012). The Simons' (1995, 2000) levers of control framework identified four strategic control elements or levers: belief systems, boundary systems, diagnostic control systems, and interactive control systems (Tessier, Otley 2012; Ferreira, Otley 2009). These four levers of control are linked to the Mintzberg's strategy concept. Mintzberg $(1991,1994)$ argued for a more flexible approach to the strategy development. He concluded that to manage strategy is to craft thought and action, control and learning, stability and change (Mintzberg et al. 1998; Nixon, Burns 2012). Simons $(1995,2000)$ defined the four control systems as follow:

- The belief system is the explicit set of organizational definitions that senior managers communicate formally and reinforce systematically to provide basic values, purpose, and direction for the organization (Simons 1995). The boundary system, on the other hand, delineates the acceptable domain of strategic activity for organizational participants (Simons 1995).

- Diagnostic control systems are formal information systems that managers use to monitor organizational outcomes and correct deviations from pre-set standards of performance (Simons 1995, 2000). On the other hand, interactive control systems are the formal information systems that managers use to involve themselves regularly and personally in the decisions of subordinates (Simons 1995, 2000). The difference between diagnostic and interactive control systems is not in their technical design features, but in the way managers use both systems.

The Simons' $(1995,2000)$ levers of control framework combines the design of management control systems (e.g. belief and boundary systems) and the use of management control systems (e.g. diagnostic and interactive control). The power of these levers of control in implementing strategies does not lie in how they are used individually, but rather in how they complement each other when they are used together (Marginson 2002; Tessier, Otley 2012). Thus, the control of an organization's strategy is achieved by integrating a passive role (design) and an active role (use) of management control systems (Widener 2007; Tessier, Otley 2012).

A deliberate strategy aims at "ensuring that managerial intentions are realized in action", while an emergent strategy emphasizes "coming to understand through the taking of actions what those intentions should be in the first place" (Nixon, Burns 2012; Mintzberg 
et al. 1998). Burgelman (1994) pointed that an emergent strategy should not be equated with lack of management, since it may reflect organizational systems and routines that enable the organization to respond quickly and flexibly to threats and opportunities (Mirabeua, Maguire 2014; Thompson et al. 2010). The four levers of control provide the motivation, measurement, learning, and control that facilitate creative adaptation and efficient goal achievement (Tessier, Otley 2012). Each of these four control systems has a different purpose in managing organizational strategies (Simons 1995; Nixon, Burns 2012).

The belief system of the organization inspires both intended and emergent strategies (Simons 1995). Belief systems appeal to the innate desires of organizational participants to belong and contribute to organizations. The belief system creates direction and momentum to fuse intended and emergent strategies together. It also provides guidance and inspiration for empowering and expanding opportunity-seeking (Tessier, Otley 2012). Top-level managers rely increasingly on empowered employees to generate new ideas to achieve a competitive advantage. Therefore, participants from all parts of an organization need to understand, as clearly as possible, the company's purposes and mission (Simons 1995, 2000). The statements achieve their ends only if employees believe, by watching the actions of senior managers, that the company's stated beliefs represent deeply rooted values (Widener 2007; Simons 2000). Thus, we can expect that the enabling role of belief systems will facilitate the realization of both deliberate and emergent strategies, by balancing different strategic objectives in organizations. Therefore, we formulate the following hypothesis:

H1: The emphasis management place on a belief system is positively related to the realization of both deliberate and emergent strategies.

Boundary systems set the rules of competition (Tessier, Otley 2012). These systems communicate the actions that employees should avoid. In this vein, Simons (1995) asserted that the most difficult part of a strategic analysis lies in determining what you do not want to do and where you do not want to compete. The purpose of a boundary system is to allow employees freedom to innovate within certain defined product markets and at acceptable levels of risk (Widener 2007; Simons 2000). Boundary systems ensure that realized strategies fall within the acceptable domain of activities. Boundary and belief systems are similar in that they both are intended to motivate employees to search for new opportunities. However, boundary systems focus on negative aspects through the constraint of behavior, while belief systems focus on positive aspects through inspiration (Simons 1995; Widener 2007). Since boundary systems provide limits of freedom, we can expect that these systems will also facilitate managers to realize intended and emergent strategies in organizations. Therefore, we formulate the following hypothesis:

H2: The emphasis management place on a boundary system is positively related to the realization of both deliberate and emergent strategies.

Diagnostic control systems are "the formal systems that managers use to monitor organizational outcomes and correct deviations" (Simons 1995; Henri 2006). Diagnostic control systems focus attention on the implementation of intended strategies (Simons 
1995), since strategy is conceived as a plan (Simons 2000). By their nature, diagnostic controls do not encourage the continuous improvement and learning of the organization, and thus they are used to implement intended strategies by measuring critical performance variables (Simons 1995). Managers can ascertain if intended strategies are realized only if those strategies are monitored by a diagnostic control system, which allows them to measure outcomes and to compare actual and expected goals (Simons 1995; Widener 2007). As planned strategic objectives are better facilitated with close monitoring, we expect that diagnostic control systems will support the adoption of intended strategic goals, rather than the realization of emergent strategies. Therefore, we formulate the following hypothesis:

H3: The emphasis management place on a diagnostic control system is positively related to the realization of deliberate strategies, but negatively related to the realization of emergent strategies.

Finally, interactive control systems expand and guide the opportunity-seeking that may result in the emergence of strategies. Interactive controls provide managers with a mechanism to learn of new strategic opportunities (Widener 2007; Tuomela 2005), which may result in emergent strategies (Mirabeua, Maguire 2014). Through an interactive use of control systems managers encourage communication among employees and stimulate the development of creativeness and innovative strategic actions. The realization of an emergent strategy will benefit from the combination of coordination and continuous learning, which is encouraged by constant discussion and interaction in the organization (Mintzberg 1991). These features all correspond with an interactive control (Naranjo-Gil, Hartmann 2007; Ferreira, Otley 2009). Thus, we expect that interactive control systems will facilitate new strategies to emerge in organizations (Simons 1995). Furthermore, Langfield-Smith (2008) argued that a deliberate strategy is a consciously intended course of action implying constant discussion about strategic actions, whereas an emergent strategy highlights the ambiguous nature of strategic decisions implying considerable flexibility and interaction (Cadez, Guilding 2008). Therefore, we formulate the following hypothesis:

H4: The emphasis management place on an interactive control system is negatively related to the realization of deliberate strategies, but positively related to the realization of emergent strategies.

Figure 1 shows our research model.

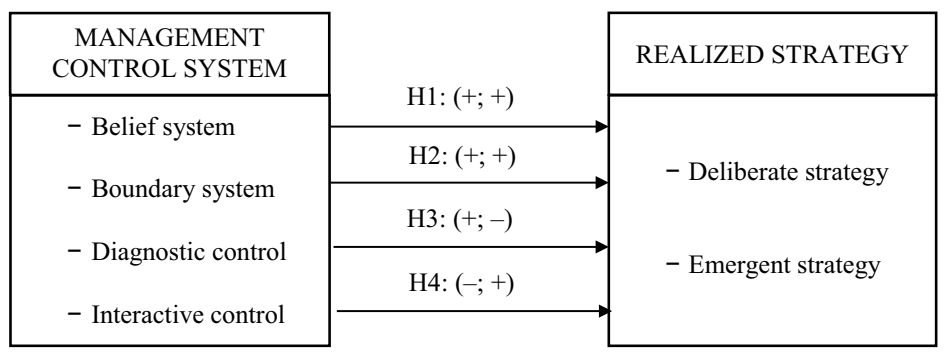

Fig. 1. Overall research model 


\section{Research method}

Our hypotheses were tested using data from the public hospital sector in Spain, which is involved in processes of strategic reorientation. Spanish health care authorities encourage hospitals to pursue different strategic objectives, such as continuous improvement in service delivery and enhanced cost efficiency (Carretero 2000; Shortell et al. 1996). These reasons assured that the issues central to this study were considered to be relevant for the population. These expectations were supported in a pilot study, which was performed, and designed in two steps: a pre-test and the design of the questionnaire. The pretest was done in three stages, following Dillman (2000): (1) interview rounds, (2) question formulation, and (3) pretests of draft versions of the questionnaire among members of the target population. A total of 18 interviews were performed in four hospitals. Through these interviews we collected ideas and comments for designing the study ${ }^{2}$.

We used the Spanish National Catalogue of Hospitals to obtain a list of all 218 public hospitals. We developed a list of CEOs from this catalogue, supported by information from internet and telephone calls to hospitals. A questionnaire survey was used to collect information on management control systems, deliberate strategies and emergent strategies. The questionnaire was designed and administrated in accordance with the guidelines of Dillman's (2000) Tailored Design Method and it was distributed among the CEOs of all 218 public hospitals in Spain. A satisfactory response rate was achieved, with 116 useful questionnaires returned of the 218 questionnaires addressed to CEOs (53.22\%). To test for validity and for potential non-response bias, we compared survey respondents with the original mailing list and compared the answers provided by early and late respondents. Chi-square tests and independent-samples t-tests did not reveal any indication of non-response bias ${ }^{3}$.

\subsection{Measurement of variables}

Deliberate and emergent strategies were measured with a Likert-type instrument adapted from Harrington et al. (2004) and Brews and Hunt (1999) ${ }^{4}$. Deliberate and emergent strategies were measured according to the specificity and number of strategic ends and means. A high specificity of ends and means is consistent with a deliberate approach, and a low specificity is consistent with a more emergent approach (Brews, Hunt 1999). Emergent strategies are related to the number and magnitude of changes to intended strategies. They are also related to the number of additive strategies that emerge between intended and realized strategies (Harrington et al. 2004). Factor analyses revealed that

\footnotetext{
${ }^{2}$ Respondents highlighted some confusing words. Most wording problems were due to the original English wording. Careful attention was paid to add clarifying words, rather than completely changing the items.

${ }^{3}$ The results of the Chi-square test for the size comparing the original mailing list and survey respondents was $\chi^{2}=1.409(\mathrm{p}=0.516)$. The results of the Chi-square test for the size comparing early and late respondents was $\chi^{2}=1.544(\mathrm{p}=0.572)$.

${ }^{4}$ A description of the questionnaire items is found in the Appendix.
} 
constructs for deliberate and emergent strategies were unidimensional with Cronbach's Alphas of 0.81 and 0.86 , respectively.

Management control systems were measured following Simons (1995) levers of control framework. We used a Likert-type instrument adapted from Widener (2007) and Naranjo-Gil and Hartmann (2007) for measuring belief, boundary, and diagnostic and interactive control systems. Belief systems were measured with questions about the use of organizational mission statements, and the communication of core values. Boundary systems were measured with questions about the use of codes of business conduct, and the communication of areas/actions that should be avoided. We measured diagnostic and interactive control systems with items reflect the main features of these types of control (Naranjo-Gil, Hartmann 2007; Widener 2007). For instance, in the case of diagnostic controls we asked managers to assess the use of management control systems for following up preset plans and goals, for following up significant exceptions and deviation, for evaluating and control subordinates tightly. In the case of interactive controls we asked managers about the use of management controls for encouraging new goals and priorities, for signaling key strategic areas, for encouraging new ideas and actions, and for involving subordinates in face-to-face discussions (Naranjo-Gil, Hartmann 2007; Simons 2000). Factor analyses revealed that every construct was unidimensional. Cronbach alpha and Composite Reliability were also satisfactory, exceeding the recommended level of 0.7 (cf. Nunnally 1978).

In our analysis we controlled for the potential effects of two variables: hospital size, which was measured as the number of beds (Abernethy, Brownell 1999), and care complexity, which was measured using objective data on the hospitals' case-mix index (Jonge et al. 2001). This index indicates the care complexity according to the average diagnosis-related group weight. A score higher than 1 indicates a hospital's case mix is more complex than the standard case $\mathrm{mix}^{5}$. The discriminant validity of the instruments was assessed by calculating the Average Variance Extracted (AVE) of each construct and by comparing the AVE's with the squared correlations of the constructs. The discriminant validity proved to be satisfactory because the AVE's were higher than the correlations in all cases (cf. Nunnally 1978).

\section{Results}

The hypotheses were analyzed using Partial Least Squares (PLS). The assessment of the measurement model in PLS is comparable with principle components analysis, while the path coefficients in the PLS structural model are interpretable as $\beta$-statistics from ordinary least squares regression (Chenhall 2005; Naranjo-Gil, Hartmann 2007). As such, PLS allows smaller sample sizes than covariance-based models. PLS does not report on the fit of the whole model. Table 1 shows the descriptive statistics of the vari-

\footnotetext{
${ }^{5}$ The diagnosis-related group classifies hospital activities into one of 500 groups expected to have similar hospital resource use, and it shows the nature an intensity of the hospital services (Pizzini 2006).
} 
ables and the demographics characteristics of our sample of CEOs ${ }^{6}$. Table 2 shows the correlations between the variables in the model. Table 2 shows that a boundary system is positively and significant related to both deliberate and emergent strategies. It also shows that a boundary system is positively related to a deliberate strategy and also to an emergent strategy, but this relationship was not significant. Table 2 shows a positive and significant relationship between a diagnostic control and a deliberate strategy. The relationship between a diagnostic control and an emergent strategy was negative but not significant. Table 2 also shows that an interactive control system is positive and significant related to both deliberate and emergent strategies.

Table 1. Descriptive statistics $(n=116)$

\begin{tabular}{lcccc}
\hline \multicolumn{1}{c}{ Variable } & Mean & SD & Theoretical range & Actual range \\
\hline 1. Belief system & 3.82 & 0.79 & $1.00-5.00$ & $1.00-5.00$ \\
2. Boundary system & 3.94 & 0.85 & $1.00-5.00$ & $1.00-5.00$ \\
3. Diagnostic system & 3.49 & 0.54 & $1.00-5.00$ & $1.00-5.00$ \\
4. Interactive system & 3.67 & 0.52 & $1.00-5.00$ & $1.00-5.00$ \\
5. Deliberate strategy & 3.28 & 0.61 & $1.00-5.00$ & $1.00-5.00$ \\
6. Emergent strategy & 2.96 & 0.49 & $1.00-5.00$ & $1.00-5.00$ \\
7. Age & 44.1 & 4.3 & ---- & $30-61$ \\
8. Tenure & 6.3 & 4.8 & --- & $1-18$ \\
9. Male (female) & $91 \%(9 \%)$ & 109.3 & ---- & $190-1230$ \\
10. Hospital size (number beds) & 336.2 & 0.16 & ---- & $0.93-1.61$ \\
11. Care complexity (case-mix) & 1.57 & & & \\
\hline
\end{tabular}

Table 2. Correlations from PLS model $(n=116)$

\begin{tabular}{lccccc}
\hline & 1 & 2 & 3 & 4 & 5 \\
\hline 1. Belief system & 1.000 & & & & \\
2. Boundary system & 0.141 & 1.000 & & & \\
3. Diagnostic control system & 0.158 & $0.242^{\mathrm{b}}$ & 1.000 & & \\
4. Interactive control system & $0.221^{\mathrm{b}}$ & 0.139 & 0.184 & 1.000 & \\
5. Deliberate strategy & $0.352^{\mathrm{a}}$ & $0.264^{\mathrm{a}}$ & $0.401^{\mathrm{a}}$ & $0.298^{\mathrm{a}}$ & 1.000 \\
6. Emergent strategy & $0.394^{\mathrm{a}}$ & 0.153 & -0.142 & $0.332^{\mathrm{a}}$ & 0.084 \\
\hline
\end{tabular}

Notes: ${ }^{\text {a }}$ Significant at 0.01 level (two tailed); ${ }^{\mathrm{b}}$ Significant at 0.05 level (two tailed).

Figure 2 displays the PLS model tested. Table 3 contains the detailed output statistics of the analysis of the path coefficients in the structural model and reports on the significance of the standardized $\beta_{\mathrm{s}}$ that resulted from this analysis, based on a bootstrapping procedure that used 500 samples with replacement. Table 3 shows support for our hypothesis 1 , since the path coefficient indicates a positive and significant relationship between a belief system and both deliberate and emergent strategies. Results in Table 3 show a positive and significant relationship between a boundary system and a delibe-

\footnotetext{
${ }^{6}$ The 218 public hospitals in Spain are classified in: 99 small hospitals (less than 250 beds); 64 medium hospitals (between 250 and 600 beds) and 55 large hospitals (more than 600 beds). We got response from $43.9 \%$ small hospitals, $33.6 \%$ medium hospitals and $22.5 \%$ large hospitals.
} 
rate strategy; however the relationship between a boundary system and an emergent strategy is positive but not significant. Thus, partial support was found for hypotheses 2. The unexpected result could be explained by the fact that boundary systems can encourage employees to search conservative strategic objectives, but it can also limit the emergency of creativeness and the search of risky strategic opportunities. The path coefficient in Table 3 shows a positive and significant relationship between a diagnostic control system and a deliberate strategy. Results also show a negative but not significant relationship between a diagnostic control system and an emergent strategy. Thus, partial support was found for hypothesis 3. A plausible explanation for this unexpected result could be that no all subordinates react to diagnostic control in the same way, thus only creative subordinates are likely to refuse any control from diagnostic system (Henri 2006; Langfield-Smith 2008). Results in Table 3 shows partial support for hypothesis 4 , since the relationships between an interactive control system and both deliberate and emergent strategies are positive and significant ${ }^{7}$. The unexpected result could be explained by the fact that management control systems are also used interactively in routine engagement with employees to review data and to follow strategic planning (Ismail 2013; Langfield-Smith 2008). These results may imply that organizations should encourage managers to use control systems interactively rather than diagnostically to implement strategies successfully.

Table 3. Results from PLS analysis (path coefficients, $\mathrm{n}=116$ )

\begin{tabular}{lcc}
\hline & Deliberate strategy & Emergent strategy \\
\hline 1. Belief system & $0.379^{\mathrm{a}}$ & $0.401^{\mathrm{a}}$ \\
2. Boundary system & $0.258^{\mathrm{a}}$ & 0.127 \\
3. Diagnostic control system & $0.407^{\mathrm{a}}$ & -0.138 \\
4. Interactive control system & $0.301^{\mathrm{a}}$ & $0.342^{\mathrm{a}}$ \\
\hline
\end{tabular}

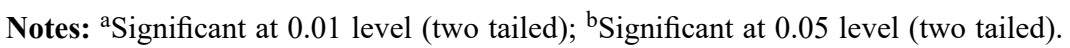

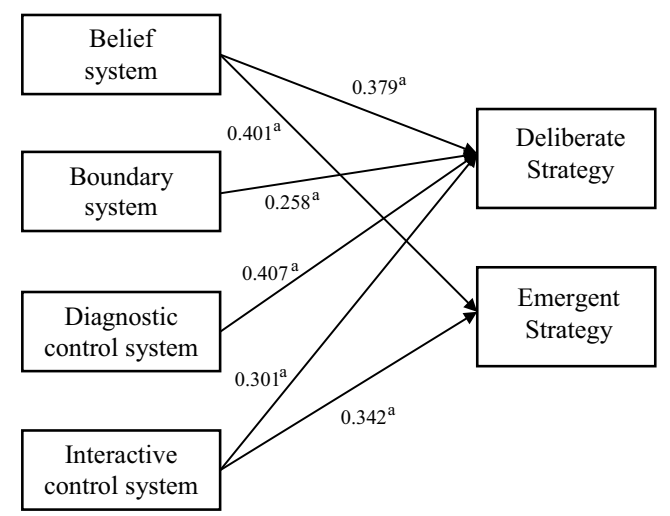

Fig. 2. Results PLS structural analysis

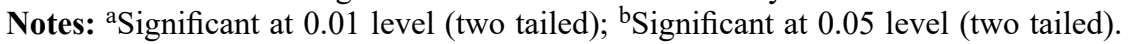

\footnotetext{
${ }^{7}$ The control variables (size and care complexity) did not reveal any significant path with management control systems (boundary, belief, diagnostic and interactive), deliberate strategy and emergent strategy.
} 


\section{Conclusions}

Based on levers of control framework, this paper analyzed how the four control systems (belief, boundary, diagnostic and interactive) work together to realize strategies. Two realized strategies were analyzed: deliberate and emergent. Results showed that management control systems complement each other to realize strategies in organizations. Thus, this paper showed empirical evidence of the Simons' framework as a control mechanism that organizations can use for facilitating intended strategies to be realized, and also for facilitating that new emergent strategies arise. We found that the belief systems and the interactive control systems are the positive energy levers that inspire managers to seek, explore and create emergent strategies. This paper looked at tensions and balances between different types of management control systems to enhance understanding how organizations can implement both deliberate and emergent strategies. Thus this paper extended the contingency-based literature on strategic management accounting by showing that strategy implementation is not only a function of the outcome of strategic decision making processes, but it also crucially depends on how management control systems are used by CEOs.

This study has also shown that a passive role (design) and an active role (use) of management control systems should be combined by CEOs to success in implementing different strategies. These results are in line with Tuomela (2005) and Widener (2007), who argued that a broad design and a flexible use of management control systems may facilitate strategy management in organizations. Our findings show the tension between the diagnostic and interactive uses of management control systems, which have enabling and constraining effects on strategy implementation. It can be concluded that a diagnostic use of management control systems appears beneficial in controlling and in implementing strategic planning. In contrast, an interactive use of management control systems appears beneficial in bringing about organizational flexibility and in crafting emergent strategies as well. Through an interactive use of control systems managers stimulate communication and break down the functional and hierarchical barriers that restrict the flow of information and thus stimulate the development of innovative actions, which may differ from what was initially planned.

This paper enhances and updates our knowledge about the design and use of management control systems in facilitating strategy implementation. This study has shown that management control systems have different effects on strategy implementation (deliberate vs. emergent). While new strategic actions and initiatives can emerge from all levels of the organization, top managers can exercise important influence by setting up mechanisms, such as management control systems, to stimulate and control new strategic opportunities throughout the organization. Thus, the failure (success) of a strategy implementation process can be seen as one example of the (un)appropriated use of management control systems for managing different strategies in organizations. The current paper provides an empirical linkage between different control systems and the way they support planned and emergent strategies. We can conclude that the four levers of control complement each other to implement business strategies. In this vein, 
we answer a recent plea in the management accounting literature for more complete explanations of the consequences of different types of management control systems in strategy management in a single study.

The findings of this paper provide a fruitful avenue for improving our understanding on the relationship between strategy implementation and management control system in public organizations. In this line, this paper answers recent calls in the literature to focus on control systems for managing strategies in the public sector (see Modell 2012). Under the new public management, managers have to use management control systems to face the challenge of balances and coordinates different strategic policies, such as offering higher quality services at lower cost. An important practical consequence of this study is that not only the design of management control systems matters for achieving different strategic priorities, but also the use of management control systems by top managers.

As any empirical study, this paper has its limitations. Some of these limitations are inherent to the survey method, such as the use of perceptual measures and the potential for common-method bias. Limitations may also be found in the lack of testing of the directions of causality due to the cross-sectional nature of the study. Cross-sectional survey is very suitable for showing relationships among variables, which is one of the requirements for causation. Future studies could analyze the relationship between management control systems and strategy by using experimental research and other research methods that are stronger at demonstrating causality. Another limitation of this paper is related to our focus on a single industry. Although we believe that the hospital sector is well suited to test our hypotheses, it may contain idiosyncrasies that have been overlooked. Future studies can test our hypotheses in a different industrial setting, which may add to the external validity of the results. In this line, future research could compare public sector organizations with private companies.

\section{Acknowledgments}

This article has benefited from comments from workshop participants at Pablo de Olavide University, RSM Erasmus University, and 2010 European Accounting Association Conference. The author would like to thank the Spanish Ministry of Science and Technologies (Project ECO2011-24613) for the support.

\section{References}

Abernethy, M. A.; Brownell, P. 1999. The role of budgets in organizations facing strategic change: an exploratory study, Accounting, Organizations and Society 24: 189-204.

http://dx.doi.org/10.1016/S0361-3682(98)00059-2

Anthony, R.; Govindarajan, V. 2007. Management control systems. Chicago, Mc-Graw-Hill: IRWIN.

Brews, P. J.; Hunt, M. R. 1999. Learning to plan and planning to learn: resolving the planning school/learning school debate, Strategic Management Journal 20: 889-913.

http://dx.doi.org/10.1002/(SICI)1097-0266(199910)20:10<889::AID-SMJ60>3.0.CO;2-F 
Burgelman, R. A. 1994. Fading memories - a process theory of strategic business exit, Administrative Science Quarterly 39(1): 24-56. http://dx.doi.org/10.2307/2393493

Cadez, S.; Guilding, C. 2008. An exploratory investigation of an integrated contingency model of strategic management accounting, Accounting, Organizations and Society 33: 836-863.

http://dx.doi.org/10.1016/j.aos.2008.01.003

Cadez, S.; Guilding, C. 2012. Strategy, strategic management accounting and performance: a configurational analysis, Industrial Management \& Data Systems 112(3): 484-501.

http://dx.doi.org/10.1108/02635571211210086

Carretero, L. 2000. Herramientas para la Gestión Clínica, Gestion Hospitalaria 11: 15-21.

Carter, C.; Clegg, S. R.; Kornberger, M. 2010. Re-framing strategy: power, politics and accounting, Accounting, Auditing and Accountability Journal 23: 573-594.

http://dx.doi.org/10.1108/09513571011054891

Chenhall, R. H. 2005. Integrative strategic performance measurement systems, strategic alignment of manufacturing, learning and strategic outcomes: an exploratory study, Accounting, Organizations and Society 30: 395-422. http://dx.doi.org/10.1016/j.aos.2004.08.001

Chenhall, R. H. 2008. Accounting for the horizontal organization: a review essay, Accounting, Organizations and Society 33(4-5): 517-550. http://dx.doi.org/10.1016/j.aos.2007.07.004

Davies, H.; Walters, P. 2004. Emergent patterns of strategy, environment and performance in a transition economy, Strategic Management Journal 25(4): 347-364.

http://dx.doi.org/10.1002/smj.380

Dillman, D. A. 2000. Mail and internet surveys: the tailored design method. New York: John Wiley and sons.

Ferreira, A.; Otley, D. 2009. The design and use of performance management systems: an extended framework for analysis, Management Accounting Research 20: 263-283.

http://dx.doi.org/10.1016/j.mar.2009.07.003

Frigotto, M. L.; Coller, G.; Collini, P. 2013. The strategy and management control systems relationship as emerging dynamic process, The Journal of Management and Governance 17: 631-656. http://dx.doi.org/10.1007/s10997-011-9198-x

Harrington, R. J.; Lemak, D. J.; Reed, R.; Kendall, K. W. 2004. A question of fit: the links among environment, strategy formulation, and performance, Journal of Business \& Management 10: $15-37$.

Henri, J. 2006. Management control systems and strategy: a resource-based perspective, Accounting, Organizations and Society 31: 529-558. http://dx.doi.org/10.1016/j.aos.2005.07.001

Ismail, T. 2013. Formatting strategy and management control system: evidence from Indonesia. International Journal of Business and Social Science 4(1): 196-205.

Jonge, P.; Huyse, F. J; Slaets, J. P.; Herzog, T.; Lobo, A.; Lyons, J. S.; Opmeer, B. C.; Stein, B.; Arolt, V.; Balogh, N.; Cardoso, G.; Fink, P.; Rigatelli, M.; Van Dijck, R.; Mellenberg, G. J. 2001. Care complexity in the general hospital: results from a European study, Psychosomatics 42(3): 204-212. http://dx.doi.org/10.1176/appi.psy.42.3.204

Langfield-Smith, K. 2008. Strategic management accounting: how far have we come in 25 years?, Accounting, Auditing \& Accountability Journal 21(2): 204-228.

http://dx.doi.org/10.1108/09513570810854400

Lowe, A.; Jones, A. 2004. Emergent strategy and the measurement of performance: the formulation of performance indicators at the microlevel, Organization Studies 25(8): 1313-1337.

http://dx.doi.org/10.1177/0170840604046344

Marginson, D. E. W. 2002. Management control systems and their effects on strategy formation at middle-management levels: evidence from a U.K. organization. Strategic Management Journal 23: 1019-1031. http://dx.doi.org/10.1002/smj.271 
Mintzberg, H. 1978. Patterns in strategy formation, Management Science 24: 934-948. http://dx.doi.org/10.1287/mnsc.24.9.934

Mintzberg, H. 1987. Crafting strategy, Harvard Business Review 65: 66-75.

Mintzberg, H. 1991. Learning 1, planning 0: reply to Igor Ansoff, Strategic Management Journal 12(6): 463-466. http://dx.doi.org/10.1002/smj.4250120606

Mintzberg, H. 1994. The rise and fall of strategic planning. New York, NY: The Free Press.

Mintzberg, H.; Ahlstrand, B.; Lampel, J. 1998. Strategy Safari: a guided tour through the wilds of strategic management. New York, NY: The Free Press.

Mintzberg, H.; Waters J. 1985. Of strategies, deliberate and emergent, Strategic Management Journal 6: 257-272. http://dx.doi.org/10.1002/smj.4250060306

Mirabeua, L.; Maguire, S. 2014. From autonomous strategic behavior to emergent strategy, Strategic Management Journal 6(8): 1202-1229. http://dx.doi.org/10.1002/smj.2149

Modell, S. 2012. Strategy, political regulation and management control in the public sector: institutional and critical perspectives, Management Accounting Research 23: 278-295.

http://dx.doi.org/10.1016/j.mar.2012.05.001

Nixon, B.; Burns, J. 2012. The paradox of strategic management accounting, Management Accounting Research 23: 229-244. http://dx.doi.org/10.1016/j.mar.2012.09.004

Naranjo-Gil, D.; Hartmann, F. 2007. Management accounting systems, top management team heterogeneity and strategic change, Accounting, Organizations and Society 32: 735-756.

http://dx.doi.org/10.1016/j.aos.2006.08.003

Nunnally, J. D. 1978. Psychometric theory. New York: McGraw-Hill.

Pizzini, M. J. 2006. The relation between cost-system design, managers' evaluations of the relevance and usefulness of cost data, and financial performance: an empirical study of US hospitals, Accounting, Organizations, and Society 31: 179-210. http://dx.doi.org/10.1016/j.aos.2004.11.001

Porter, M. 1985. Competitive advantage: creating and sustaining superior performance. New York, NY: The Free Press.

Schultz, F. C.; Pal, S.; Swan, D. A. 2004. Who should lead a healthcare organization: MDs or MBAs?, Journal of Healthcare Management 49(2): 103-117.

Shortell, S. M.; Gillies, R. R.; Anderson, D. A.; Erickson, K. M.; Mitchell, J. B. 1996. Remaking heath care in america: building organized delivery systems. San Francisco, CA.: Jossey Bass.

Simons, R. 1995. Levers of control. Boston, MA: Harvard Business School Press.

Simons, R. 2000. Performance measurement and control systems for implementing strategy. Upper Saddle River, NJ: Prentice Hall.

Skaerbaek, P.; Tryggestad, K. 2010. The role of accounting devices in performing corporate strategy, Accounting, Organizations and Society 35: 108-124.

http://dx.doi.org/10.1016/j.aos.2009.01.003

Snow, C.; Hambrick, D. C. 1980. Measuring organizational strategies: some theoretical and methodological problem, Academy of Management Review 4: 527-538.

Tessier, S.; Otley, D. 2012. A conceptual development of Simons' Levers of control framework, Management Accounting Research 23(3): 171-185. http://dx.doi.org/10.1016/j.mar.2012.04.003

Thompson, A. A.; Strickland, A. J.; Gamble, J. E. 2010. Crafting and executing strategy. New York: McGraw-Hill.

Tuomela, T. 2005. The interplay of different levels of control: a case study of introducing a new performance measurement system, Management Accounting Research 16: 293-320.

http://dx.doi.org/10.1016/j.mar.2005.06.003

Widener, S. K. 2007. An empirical analysis of the levers of control framework, Accounting, Organizations and Society 32: 757-788. http://dx.doi.org/10.1016/j.aos.2007.01.001 


\section{APPENDIX}

\section{Questionnaire items}

\section{Strategic ends specificity}

\section{Please indicate which one statement most closely describes your organization}

- No ends have been developed for our organization in the strategy formation process.

- A few (less than three) ends have been developed for our organization in the strategy formation process, but they remain undocumented and informal.

- A few (less than three) ends have been developed for our organization and formally documented in the strategy formation process.

- A number (greater than three) of ends have been developed for our organization in the strategy formation process, but they remain undocumented and informal.

- A number (greater than five) of ends have been developed for our firm and formally documented in the strategy formation process.

\section{Indicate in general the specificity of your organization's ends}

For example, very specific ends would be those which identify exact objectives, such that little need for interpretation or further explanation exists. Please indicate the one statement which best describes your organization's ends:

(1) Very specified; (2) Unspecified; (3) Both Specific and Specific; (4) Very specific;

(5) Unspecified.

\section{Strategic means specificity}

\section{Please indicate which one statement best describes your organization}

- No specific strategic plans or policies have been developed to guide the organization.

- Firm strategies have tended to emerge as the organization learns from its experiences.

- The organization has a broad strategic plan in place, but this plan is considered a loose guide and is not strictly adhered to, and tends to change as the organization succeeds or fail in its activities. This plan contains no specific, detailed action plans or programs that the firm is expected to implement. Strategies have tended to develop and emerge over time.

- The organization has developed a strategic plan, which includes specifically developed means, but this plan is considered a loose guide, which is either ignored, or loosely followed. The plan contains no specific, detailed action plans or programs that the organization is expected to implement.

- The organization has a carefully developed strategic plan, detailing on a step-bystep basis a number of specific actions and programs the firm is implementing, or will implement in order to achieve its objectives, and thus accomplish its ends. This plan, developed after careful deliberation, is typically fully formed and complete 
once the planning cycle is finished. The firm is currently implementing this plan, as outlined.

\section{Please indicate in general the specificity of your organization's "means"}

For example, very specific means would describe exact plans or programs the organization must implement, and set out on a detailed basis the steps required to achieve implementation. Very unspecified means would be broad, general statements of an organization's strategic intention, with little detail or steps intended to guide specific action. Please indicate the one statement which best describes your organization's means: (1) Very specified; (2) Unspecified; (3) Both Specific and Specific; (4) Very specific; (5) Unspecified.

\section{Belief system}

Please indicate the extent to which the following items describe your organization ( 1 = not descriptive, 5 = very descriptive):

- Our mission statement clearly communicates the organization's core values to our employees.

- Top managers communicate core values to our employees.

- Our employees are aware of the organization's core values.

- Our mission statement inspires our employees.

\section{Boundary system}

Please rate the extent to which you agree or disagree with the following $(1=$ strongly disagree; 5 = strongly agree):

- Our organization relies on a code of business conduct to define appropriate behavior for our employees.

- Our code of business conduct informs our employees about behaviors that are off-limits.

- Our organization has a system that communicates to our employees risks that should be avoid.

- Our employees are aware of the organization's code of business conduct.

\section{Interactive control system}

According to the following descriptions, please indicate the extent to which you use the Management Accounting System (1 = strongly disagree; 5 = strongly agree):

- Debate data assumptions and actions plans.

- Challenge new ideas and ways for doing tasks.

- Involvement in a permanent discussion with subordinates.

- Learning tool. 


\section{Diagnostic control system}

According to the following descriptions, please indicate the extent to which you use the Management Accounting System ( 1 = strongly disagree; 5 = strongly agree):

- Follow up significant exceptions and deviations.

- Evaluate and Control subordinates tightly.

- Follow up preset plans and goals.

- Align performance measures with strategic goals.

David NARANJO-GIL is Professor of Management Accounting and Control at Pablo de Olavide University in Seville, Spain. He teaches management control in various postgraduate and $\mathrm{PhD}$ programmes. His research activities focus on investigating the role of strategic management and control systems in healthcare organizations. He is also focus on investigating the role of performance management in team-based and network-like structures. He has published widely on these topics both nationally and internationally. 